\title{
Ethylene-octene copolymer (POE) toughened polyamide 6/polypropylene nanocomposites: Effect of POE maleation
}

\author{
M. U. Wahit ${ }^{*}$, A. Hassan 1, Z. A. Mohd Ishak ${ }^{2}$, T. Czigány 3 \\ ${ }^{1}$ Faculty of Chemical and Natural Resources Engineering, Universiti Teknologi Malaysia, 81310 Skudai, Johor, Malaysia \\ ${ }^{2}$ School of Materials and Mineral Resources Engineering, Universiti Sains Malaysia, Engineering Campus, 14300 Nibong \\ Tebal, Penang, Malaysia \\ ${ }^{3}$ Department of Polymer Engineering, Faculty of Mechanical Engineering, Budapest University of Technology and \\ Economics, H-1111 Budapest, Múegyetem rkp. 3, Hungary
}

Received 23 January 2009; accepted in revised form 15 March 2009

\begin{abstract}
Ethylene-octene elastomer (POE) and ethylene-octene elastomer grafted maleic anhydride (POEgMAH) toughened nanocomposites of polyamide 6/polypropylene (PA6/PP) containing $4 \mathrm{wt} \%$ organophilic modified montmorillonite (MMT) were produced by melt compounding followed by injection moulding. The PA6/PP composition was kept constant (PA6/PP $=70 / 30$ parts) while the elastomer (either POE or POEgMAH) content varied between 5 and $20 \mathrm{wt} \%$. PP grafted maleic anhydride (PPgMAH) was used to compatibilize the blend system. The impact strength of the nanocomposite system was examined by the conventional Izod impact test at room temperature (RT). In addition, linear elastic fracture mechanics (LEFM) approach was used to study the fracture response of the notched three point bending type specimens at room temperature $(\mathrm{RT})$ and $-40^{\circ} \mathrm{C}$. Fracture surfaces of the broken specimens were examined using scanning electron microscopy. The results show that while POEgMAH can remarkably improve the compatibility between PA6 and the elastomer thus increasing the toughness, the unmodified POE has less significant contribution to PA6/PP/organoclay toughness. Elastomer domains of POEgMAH show a finer and more uniform dispersion than that of POE in the $\mathrm{PA} 6 / \mathrm{PP} /$ organoclay matrix. It is also observed that the toughness increased with the increasing elastomer concentration for both unmaleated and maleated POE.
\end{abstract}

Keywords: nanocomposites, fracture toughness, impact strength, linear elastic fracture mechanics, ethylene-octene elastomer

\section{Introduction}

Polymer-layered silicate nanocomposites have attracted increasing interest from both scientific and industrial perspectives because this new class of materials shows significant improvements in mechanical properties, barrier properties and thermal resistance at lower clay loading compared to pristine matrix [1]. In the last few years, much effort has been devoted to develop the thermoplastic nanocomposites based on blends of two or more polymeric materials, i.e. binary or ternary blends [2-6].

However, for any single thermoplastics nanocomposites system such as polyamide 6 (PA6) nanocomposites, incorporation of organoclay at high loading usually resulted in a severe embrittlement manifested in a drop of the impact strength and elongation at break $[2,7,8]$. For the thermoplastic blend nanocomposites system, Chow et al. [3] reported that PA6/PP nanocomposites exhibited 
improvement in modulus and strength as compared to the pristine PA6/PP but at the expense of toughness. A similar observation has also been reported for micro-composites based on another blend system [5].

The most widely applied method to overcome this drawback is blending with elastomers such as maleated ethylene-propylene copolymer (EPRgMAH) $[3,7]$ and maleated styrene-ethylene-butadienestyrene rubber (SEBSgMAH) [9-11]. According to González et al. [11], the addition of up to $6 \%$ of an organoclay to a 70/30 PA6/SEBSgMAH blend led to ternary compounds combining the stiffness improvement due to the inclusion of clay and the toughening effect of the rubber. It was shown that in the 70/30 blend with $3 \%$ organoclay, supertough behaviour of the nanocomposite was accomplished with a modulus increase of $44 \%$ with respect to the pure PA6 matrix.

However, to our knowledge not many papers had attempted to examine the fracture toughness of rubber toughened PA6/PP nanocomposites using linear elastic fracture mechanics (LEFM) approach. The objective of our study is to investigate the effectiveness of ethylene-octene elastomer (POE) and ethylene-octene elastomer grafted maleic anhydride (POEgMAH) as an impact modifier for PA6/PP/organoclay blends system using conventional Izod impact test and LEFM approach. POE, a relatively novel polyolefin elastomer, was developed by Dow Chemical Co. using a metallocene catalyst. Compared with EPR, POE typically exhibits easier mixing and better dispersion when blended with PP [7, 12-14]. In our previous work, POE was used as a toughening agent to form rubber-toughened PA6/PP nanocomposites [7, 14, 15]. The result showed that the addition of POE to the PA6/PP (70/30) nanocomposites improved the toughness of the nanocomposites but with limited success due to insufficient compatibility between PA6 and POE.

Conventionally, toughness has been characterized by the Izod impact test. However, the Izod impact test data cannot be used for design purposes, although they can be used for comparing the toughness between different polymer systems. With the objective to characterize toughness of polymer nanocomposites with greater accuracy, many researchers have adopted fracture mechanics approach in their studies [2, 16, 17].

Furthermore, the toughness evaluation of PA6/PP/ elastomer nanocomposites, particularly fracture toughness, has not been systematically investigated. Only few studies can be found in the literature on the fracture behavior of PA6/PP/elastomer nanocomposites. The results from our previous work have shown that for PA6/PP blend with the $70 / 30$ blend ratio, the toughness of the blends increased significantly while the strength and stiffness of PA6 was not much affected as compared to other blend ratio i.e. 60/40 and 50/50 [7]. This is the reason why in this study varying amount of unmaleated and maleated POE have been incorporated to 70/30 PA6/PP nanocomposites. Particular attention will also be paid to the fracture toughness of the nanocomposites system measured using LEFM.

\section{Materials and sample preparation}

The blends used in this work are described in Table 1. The PP (SM 240) was obtained from Titan PP Polymers, Johor Bahru, Malaysia. The melt flow index (MFI) and density were $25 \mathrm{~g} / 10 \mathrm{~min}$ and $0.9 \mathrm{~g} / \mathrm{cm}^{3}$ respectively. The PA6 (Amilan CM 1017) was a commercial product of Toray Nylon

Table 1. PA6/PP (70/30) nanocomposites blend composition [wt\%]

\begin{tabular}{|c|c|c|c|c|c|c|}
\hline Designation & Composition & $\begin{array}{c}\text { PA6/PP } \\
(70 / 30)\end{array}$ & PPgMA & $\begin{array}{c}\text { Organoclay } \\
1.30 \mathrm{TC}\end{array}$ & POE & POEgMAH \\
\hline $\mathrm{BC}$ & PA6/PP/PPgMAH & 95 & 5 & & & \\
\hline $\mathrm{BC} / \mathrm{F}$ & PA6/PP/PPgMAH/1.30TC & 91 & 5 & 4 & & \\
\hline $\mathrm{BC} / \mathrm{F} / \mathrm{E} 5$ & PA6/PP/PPgMAH/1.30TC/POE & 86 & 5 & 4 & 5 & \\
\hline $\mathrm{BC} / \mathrm{F} / \mathrm{E} 10$ & PA6/PP/PPgMAH/1.30TC/POE & 81 & 5 & 4 & 10 & \\
\hline $\mathrm{BC} / \mathrm{F} / \mathrm{E} 15$ & PA6/PP/PPgMAH/1.30TC/POE & 76 & 5 & 4 & 15 & \\
\hline $\mathrm{BC} / \mathrm{F} / \mathrm{E} 20$ & PA6/PP/PPgMAH/1.30TC/POE & 71 & 5 & 4 & 20 & \\
\hline $\mathrm{BC} / \mathrm{F} / \mathrm{mE} 5$ & PA6/PP/PPgMAH/1.30TC/POEgMAH & 86 & 5 & 4 & & 5 \\
\hline $\mathrm{BC} / \mathrm{F} / \mathrm{mE} 10$ & PA6/PP/PPgMAH/1.30TC/POEgMAH & 81 & 5 & 4 & & 10 \\
\hline $\mathrm{BC} / \mathrm{F} / \mathrm{mE} 15$ & PA6/PP/PPgMAH/1.30TC/POEgMAH & 76 & 5 & 4 & & 15 \\
\hline $\mathrm{BC} / \mathrm{F} / \mathrm{mE} 20$ & PA6/PP/PPgMAH/1.30TC/POEgMAH & 71 & 5 & 4 & & 20 \\
\hline
\end{tabular}


Resin AMILAN, Tokyo, Japan. The MFI at $230^{\circ} \mathrm{C}$ and $2.16 \mathrm{~kg}$ load and the density were $35 \mathrm{~g} / 10 \mathrm{~min}$ and $1.14 \mathrm{~g} / \mathrm{cm}^{3}$, respectively. The maleated PP (PPgMA) was Orevac CA 100 with 1 wt $\%$ maleic anhydride (MA) produced by ATOFINA, Duteaux, France. The impact modifier, POE grade Engage 8150, was supplied by DuPont Dow Elastomers, Wilmington DE, USA. Its octene content and melt flow rate were $25 \mathrm{wt} \%$ and $0.5 \mathrm{~g} / 10 \mathrm{~min}$, respectively. Ethylene octane elastomer grafted maleic anhydride (POEgMAH) Fusabond NMN 493 D (medium MAH graft level) was a commercial product of Dupont, Wilmington DE, USA. Its melt flow index is $1.6 \mathrm{~g} / 10 \mathrm{~min}$. The organoclay (Nanomer 1.30TC) was a commercial product of Nanocor Inc., Arlington Heights IL, USA. It was a white powder containing montmorillonite (MMT) (70 wt $\%$ ) intercalated by octadecylamine (30 wt $\%$ ). Following pre-designed composition ratios, PA6, PP, PPgMAH, MMT and elastomer were dry blended in a tumble mixer, and then compounded by the simultaneous addition of all components to a Berstoff co-rotating twin screw extruder. The barrel temperature was maintained at 200,220, 230 and $240^{\circ} \mathrm{C}$ from hopper to die, and the screw rotation speed was fixed at $50 \mathrm{rpm}$. Prior to blending, PA6 pellets were dehumidified using a dryer at $80^{\circ} \mathrm{C}$ for $8 \mathrm{~h}$. The extruded materials were injection moulded into standard tensile, flexural and Izod impact specimens using a JSW Model NIOOB II injectionmoulding machine with a barrel temperature of $210-240^{\circ} \mathrm{C}$. Specimens were tested dry, as moulded.

\subsection{Izod impact test}

The notched Izod impact strength of the materials was measured with a Toyoseiki impact tester according to ASTM D256 (A). All specimens had a dimension of $62 \mathrm{~mm} \times 12.3 \mathrm{~mm} \times 3.2 \mathrm{~mm}$. For each kind of blend, five specimens were tested and the average value is given.

\subsection{Fracture toughness}

The fracture toughness of the various nanocomposites systems was determined at high test speed. The notched three point bending bars were fractured by an instrumented impact pendulum (CEAST) equipped with DAS 800 advanced data acquisition unit at an impact velocity of $v=3.7 \mathrm{~m} / \mathrm{s}$, both at

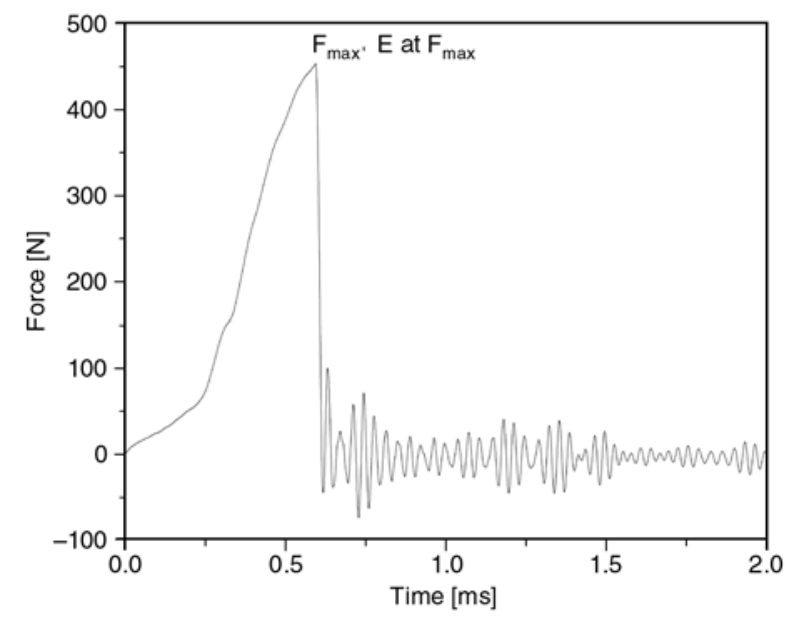

Figure 1. Characteristic force-time traces due to the impact of notched Charpy specimens

room temperature $(\mathrm{RT})$ and $-40^{\circ} \mathrm{C}$. The notch was produced by saw and razor blade tapping. Impacting of the specimens occurred under the following conditions: mass of the striker: $2.19 \mathrm{~kg}$; striker working range: $0.545 \mathrm{kN}$.

From the fractograms recorded as shown as an example in Figure 1, the maximum load $\left(F_{\max }\right)$, and the energy absorbed up to $F_{\max }$ (energy required for fracture initiation, $E_{\text {init }}$ ) were analyzed. For $K_{c}$ (based on $F_{\max }$ ) and $G_{c}$ (based on $E_{\text {init }}$ ) determination, the method adopted in ISO13586 was used [18].

\section{Results and discussion}

\subsection{Effect of elastomer content}

The Izod impact strength and fracture toughness, $K_{c}$ and fracture energy, $G_{c}$ of the neat PA6/PP blends and PA6/PP/organoclay nanocomposites as control materials are listed in Table 2. It is noted that the addition of $4 \mathrm{wt} \%$ organoclay has reduced the toughness of the nanocomposites. The Izod impact strength was reduced from 8.6 to $5.3 \mathrm{~kJ} / \mathrm{m}^{2}$, which is about $40 \%$. Wang et al. [19] reported that the impact strength decreased from $115 \mathrm{~J} / \mathrm{m}$ for the

Table 2. Mechanical properties of the neat PA6/PP (70/30) and the PA6/PP (70/30)/organoclay

\begin{tabular}{|l|c|c|c|}
\hline \multirow{2}{*}{\multicolumn{1}{|c|}{ Properties }} & \multirow{2}{*}{$\begin{array}{c}\text { Testing } \\
\text { condition }\end{array}$} & \multicolumn{2}{c|}{ System } \\
\cline { 3 - 4 } & BC & BC/F \\
\hline Impact strength $\left[\mathrm{kJ} / \mathrm{m}^{2}\right]$ & $\mathrm{RT}$ & 8.6 & 5.3 \\
\hline$K_{c}\left[\mathrm{MPa} \cdot \mathrm{m}^{1 / 2}\right]$ & $-40^{\circ} \mathrm{C}$ & 2.7 & 2.4 \\
\hline$K_{c}\left[\mathrm{MPa} \cdot \mathrm{m}^{1 / 2}\right]$ & $\mathrm{RT}$ & 8.0 & 5.6 \\
\hline$G_{c}\left[\mathrm{~kJ} / \mathrm{m}^{2}\right]$ & $-40^{\circ} \mathrm{C}$ & 3.5 & 3.3 \\
\hline$G_{c}\left[\mathrm{~kJ} / \mathrm{m}^{2}\right]$ & \multicolumn{2}{c}{} \\
\hline
\end{tabular}


neat PA6/PP to $17 \mathrm{~J} / \mathrm{m}$ for PA6/PP filled with $5 \mathrm{wt} \%$ organoclay.

According to Stevenson [20], there are two main reasons why fillers have detrimental effects on the impact resistance. The first reason is that a significant volume fraction of the polymer, which can dissipate stress through the shear yielding or crazing mechanism, is replaced by the filler, which generally cannot deform and dissipate stress easily. The ability of the material to dissipate stress is therefore reduced. However, this is particularly true at high concentration of filler. The second reason is that certain fillers may hinder the local chain motions of the polymer molecules that enable them to shear yield, what can sharply decrease the impact resistance of the materials. It is also possible that polymer nanocomposites inherently contain incomplete dispersion of nanoparticles, which form aggregates that causes premature crack formation due to poor adhesion between nanparticles and matrix. The presence of exfoliated nanoparticles may also restrict molecular mobility of the surrounding matrix material, which in turn leads to the reduction of impact strength and toughness [21]. However, this drawback is believed to be overcome by the incorporation of a rubber phase.

In the subsequent steps, this research has been directed towards improving the toughness of PA6/PP nanocomposites by the incorporation of $\mathrm{POE}$ as an impact modifier. The notched Izod impact strength of the ternary blend nanocomposites is shown as a function of POE concentration in Figure 2. The effect of POE concentration on the Izod impact strength was measured at $R T$. A minor increment in impact strength was obtained with

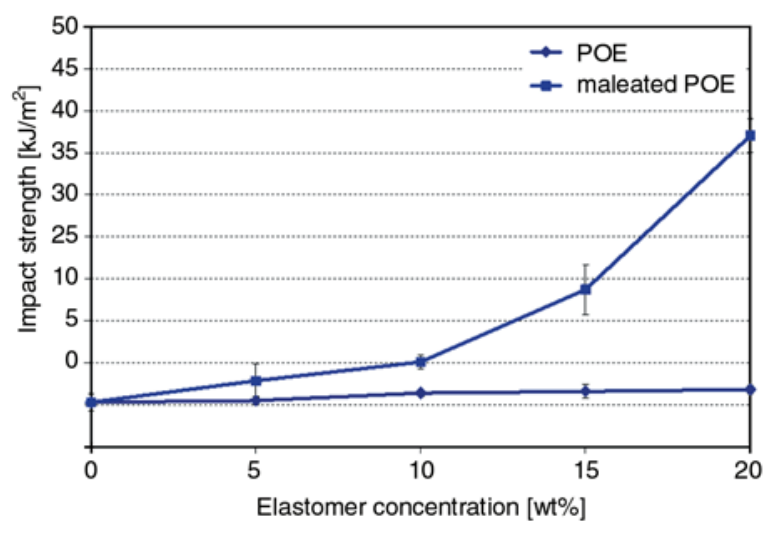

Figure 2. Effect of elastomer concentration on the Izod impact strength of rubber-toughened PA6/PP nanocomposites

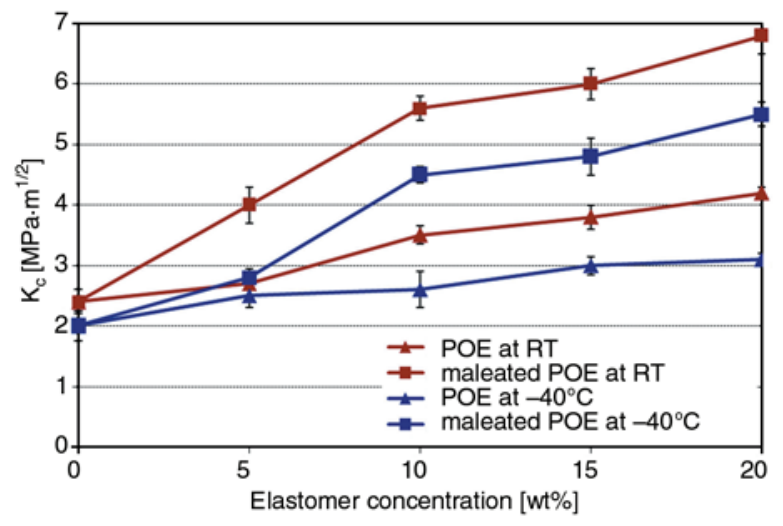

Figure 3. Effect of elastomer content on the $K_{c}$ of rubbertoughened PA6/PP nanocomposites at high test speed

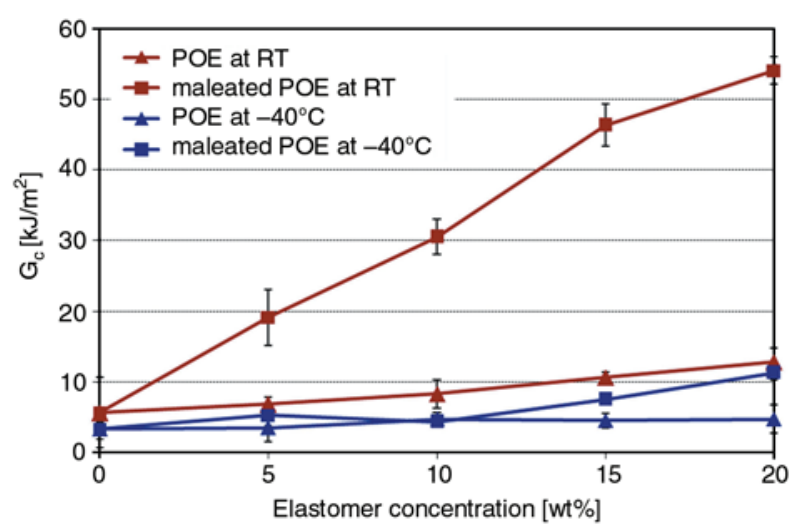

Figure 4. Effect of elastomer content on the $G_{c}$ of rubbertoughened PA6/PP nanocomposites at high test speed

increasing POE concentration in the blends despite the fact that POE is incompatible with PA6.

The variation of $K_{c}$ and $G_{c}$ of all nanocomposites as a function of POE loading at two different temperatures are shown in Figures 3 and 4. As expected, $K_{c}$ and $G_{c}$ show a similar trend with Izod impact strength where it increases linearly with increasing POE loading. It is also observed in Figures 3 and 4 that the all nanocomposites exhibit higher value of $K_{c}$ and $G_{c}$ at RT than at $-40^{\circ} \mathrm{C}$.

The enhancement in the toughness could be explained as follows; when PPgMAH was added to PA6/PP, the interfacial adhesion between PA6 and PP was improved by forming PA6gPP copolymer $[3,14]$. In addition to that, due to the structural similarity, there is a possible intermolecular attraction (physical entanglement) between PP and POE. As a result, the formation of $\mathrm{PA} 6 \mathrm{gPP}$ and physical entanglement $\mathrm{PP} / \mathrm{POE}$ contributed to the improvement of the compatibility between PA6 and POE. In addition, it is speculated that hydrogen bonding 


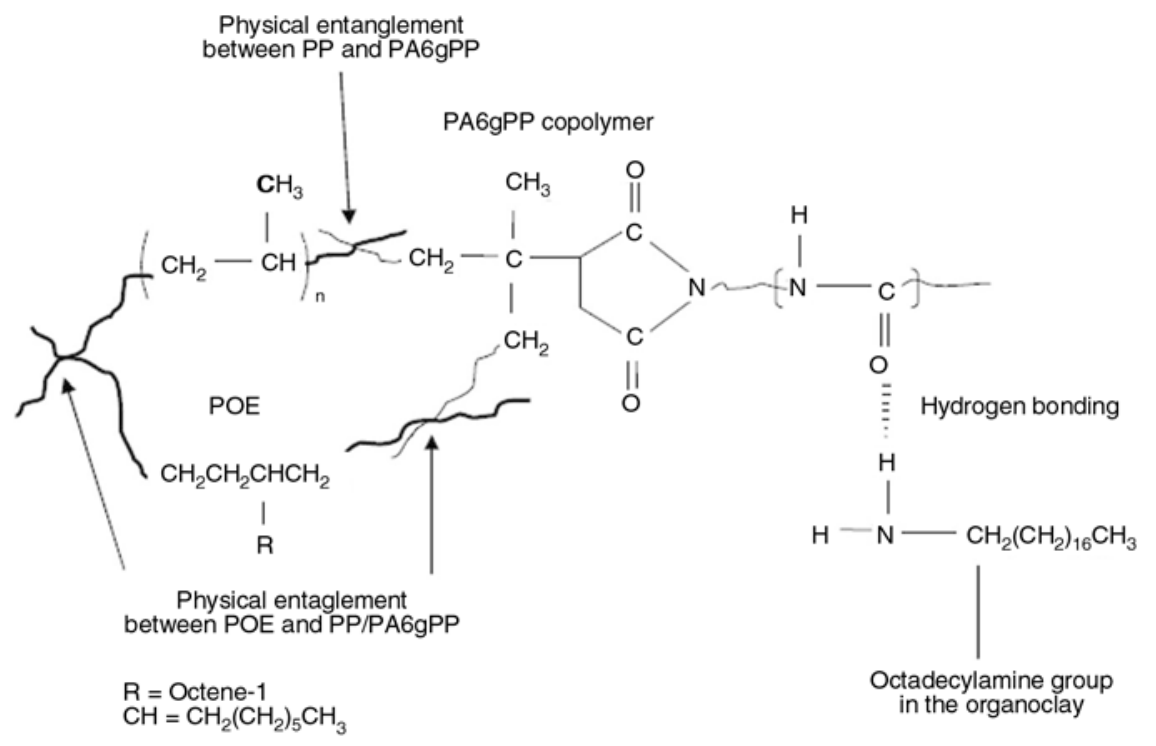

Figure 5. Interaction of $\mathrm{POE}$ and PA6gPP

could form between the amide group of the PA6gPP copolymer and the octadecylamine group of the organoclay intercalant. Figure 5 shows the proposed interaction between POE and PA6gPP copolymer nanocomposites.

Although the incorporation of POE elastomer did increase the toughness of the nanocomposites, the extent of toughening even at high POE content is well below that achieved without organoclay reinforcement. In other words, the addition of POE is not able to fully compensate the reduction in toughness caused by the organoclay. This limited improvement showed that the compatibilization of PA6/PP blends using PPgMAH is insufficient to ensure the compatibility of POE and PA6. In addition, the limited improvement of toughness properties may also be attributed to high polarity differences between POE and PA6, making this binary blend an immiscible system $[3,7,14,15$, $22]$. The problems of incompatibility can be overcome by the incorporation of either a block or graft copolymer having segments that may interact with each polymer component, or functionalized polymer that reacts with one or both polymers, leading to in-situ compatibilization during mixing process [23-25].

\subsection{Effect of rubber functionality}

Figure 2 shows the effect of rubber functionality on the impact strength of the nanocomposites. It is interesting to note that the impact strength of the nanocomposites toughened by POEgMAH (10 wt \%) increased around twice higher than that of pure PA6/PP blend and PA6/PP/organoclay. This indicates the effectiveness of POEgMAH as a toughening agent for PA6 as well as a compatibilizer for the PA6/PP blends. The increase in impact strength suggested better stress transfer across the interfaces in the nanocomposites and blends containing maleated rubber [26]. According to Yu et al. [23], if the rubber phase is highly dispersed, it acts as an effective stress concentrator and enhances both crazing and shear yielding in the matrix. Since both processes can dissipate large amounts of energy, there is a significant increase in the toughness of the blends.

Characteristic force-time traces registered during fracture of the notched three point bending specimens for the PA6/PP nanocomposites toughened by POE and maleated POE (10 wt $\%$ ) are shown in Figure 6. Both samples fractured in brittle manner, hence the specimens broke immediately once $F_{\max }$ was reached. However, from the fractograms, it is revealed that the Fmax value of the latter is higher compared to the former which leads to the higher $K_{c}$ value.

The effect of maleated POE loading on the Izod impact strength, $K_{c}$ and $G_{c}$ of the nanocomposites are shown in Figures 3 and 4. It can be seen that in all cases the Izod impact strength, $K_{c}$ and $G_{c}$ of the nanocomposites increase with the elastomer content. The significant enhancement of the Izod impact strength, $K_{c}$ and $G_{c}$ of the POEgMAH sys- 

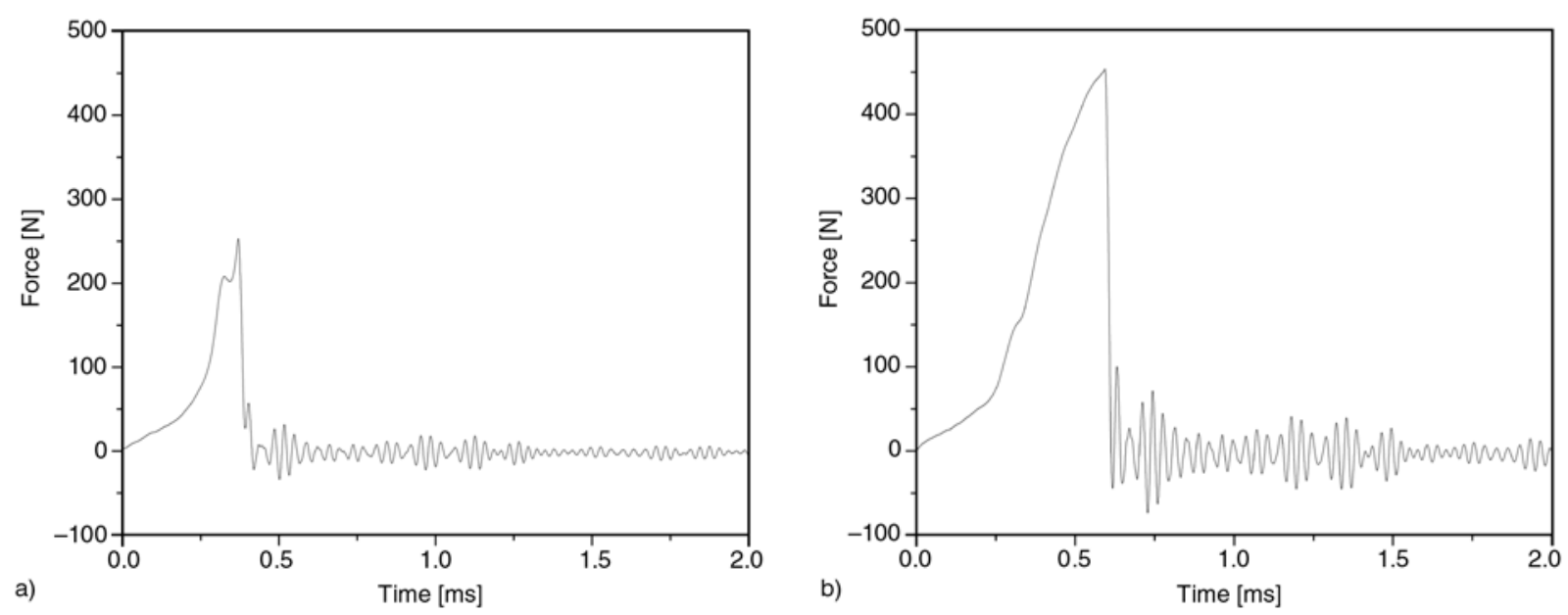

Figure 6. Comparison of $F-t(R T)$ traces of impacted notched Charpy specimens of a) PA6/PP/organoclay/POE, b) PA6/PP/organoclay/POEgMAH
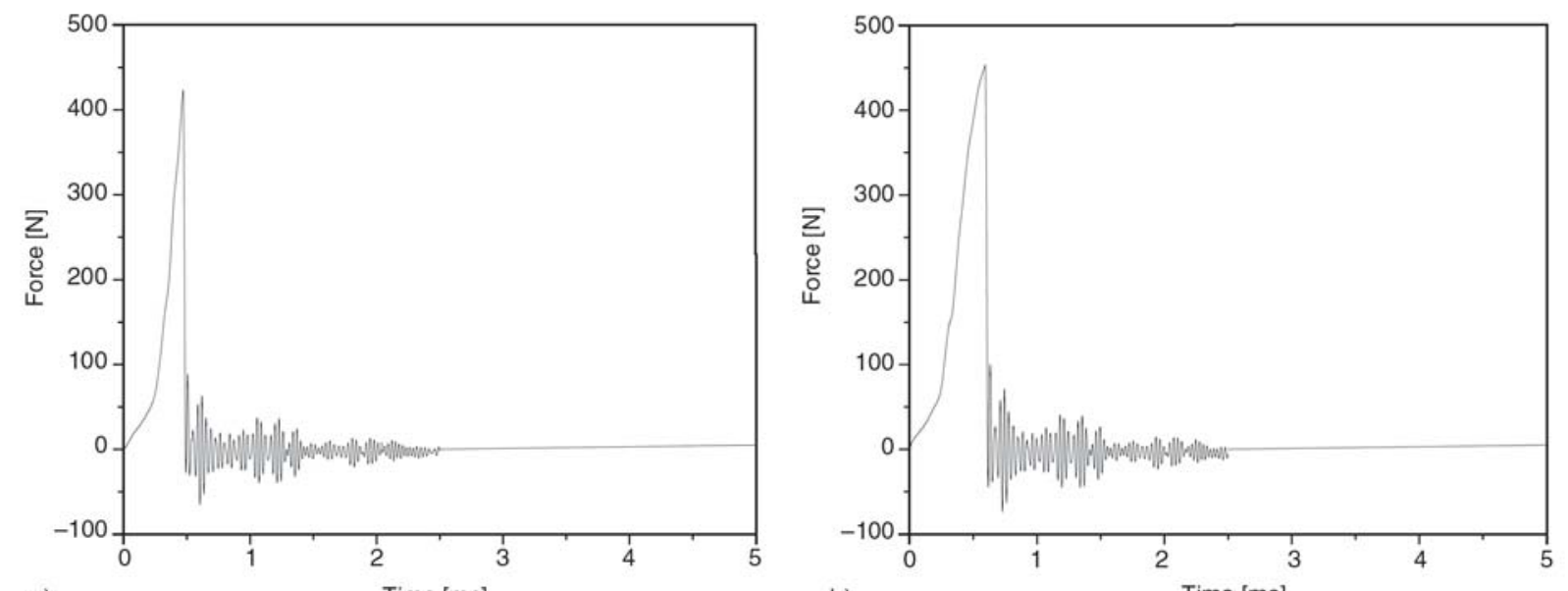

a)

b)
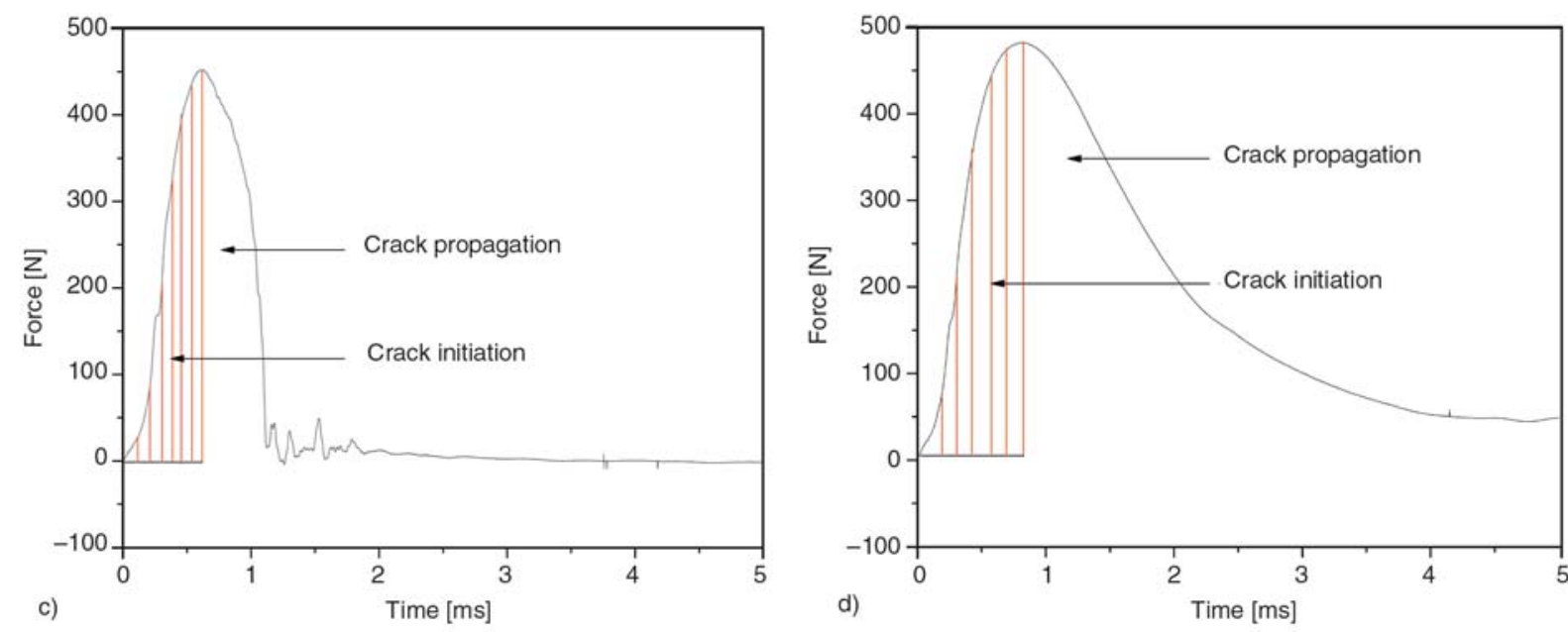

Figure 7. Comparison of $F-t(R T)$ traces of impacted notched Charpy specimens of POEgMAH toughened PA6/PP/organoclay with different POEgMAH concentration a) 5, b) 10, c) 15, d) $20 \mathrm{wt} \%$

tem compared to POE system was observed. It was also found that the increment of the Izod impact strength is noteworthy for the nanocomposites with higher maleated POE content reaching a value of $37 \mathrm{~kJ} / \mathrm{m}^{2}$, which is more than four times higher than that of the PA6/PP blends. Figure 7 shows the $F-t$ fractograms of the POEgMAH toughened PA6/PP nanocomposites with different concentrations of POEgMAH. It can be seen that the Fmax value increased as the POEgMAH concentration 
increased. It is interesting to note that by comparing the $F-t$ traces in Figure $7 \mathrm{~b}$ and Figure $7 \mathrm{c}$, the improvement in toughness of the nanocomposites becomes more apparent. The fractograms indicate that the nanocomposites failed in controlled fractured mode with considerable crack propagation (Figures 7c and 7d).

These phenomena were caused by the presence of the anhydride group of POEgMAH that reacts with the terminal amino group of PA6 during melt compounding and forms the PA6 grafted POE (PA6gPOE) copolymer subsequently as schematically shown in Figure 8 . The formation of PA6gPOE will improve the interfacial bonding between PA6 and PP. Figure 9 shows the proposed interaction between the POEgMAH, PA6gPP, PP and organoclay. This behaviour confirms previously published results demonstrating that SEBSgMAH is an efficient compatibilizer as well as impact modifier for PA6/PP blends [22]. Li et al. [27] in their work on nylon 11/POE have revealed that all nylon 11/POEgMAH blends showed higher impact strength than nylon11/POE. Yu et al. [23] obtained around five times improvement in the notched impact strength of PA6 with the incorporation of $20 \mathrm{wt} \%$ of maleated POE.

The elastomer functionality is also expected to have an important effect on the morphology of the blends, and this issue is examined here. Figure 10 presents the SEM micrograph taken from the cryogenically fractured surfaces of PA6/PP nanocomposites toughened with POE and POEgMAH. As shown in Figure 10a, it is observed that the separated spherical particles are mainly POE and the black pits correspond to sites where POE particles were extracted from the PA6/PP matrix. The immiscibility of POE and PA6 resulted in the phase separation of POE particles in the blends. The edges of the holes where POE have been extracted are quite smooth. This confirms that a weak interfacial adhesion is present between the two phases and reveals low compatibility between PA6 and POE. On the contrary, the SEM micrograph of PA6/PP/organoclay/POEgMAH as shown in Figure 10b presents the homogenous character of the morphology of the blends. Fewer particles are observed on the fracture surface of nanocomposites with maleated POE. The fracture surface is also characterized by a non-broken PA6/POEgMAH interface. Therefore, the

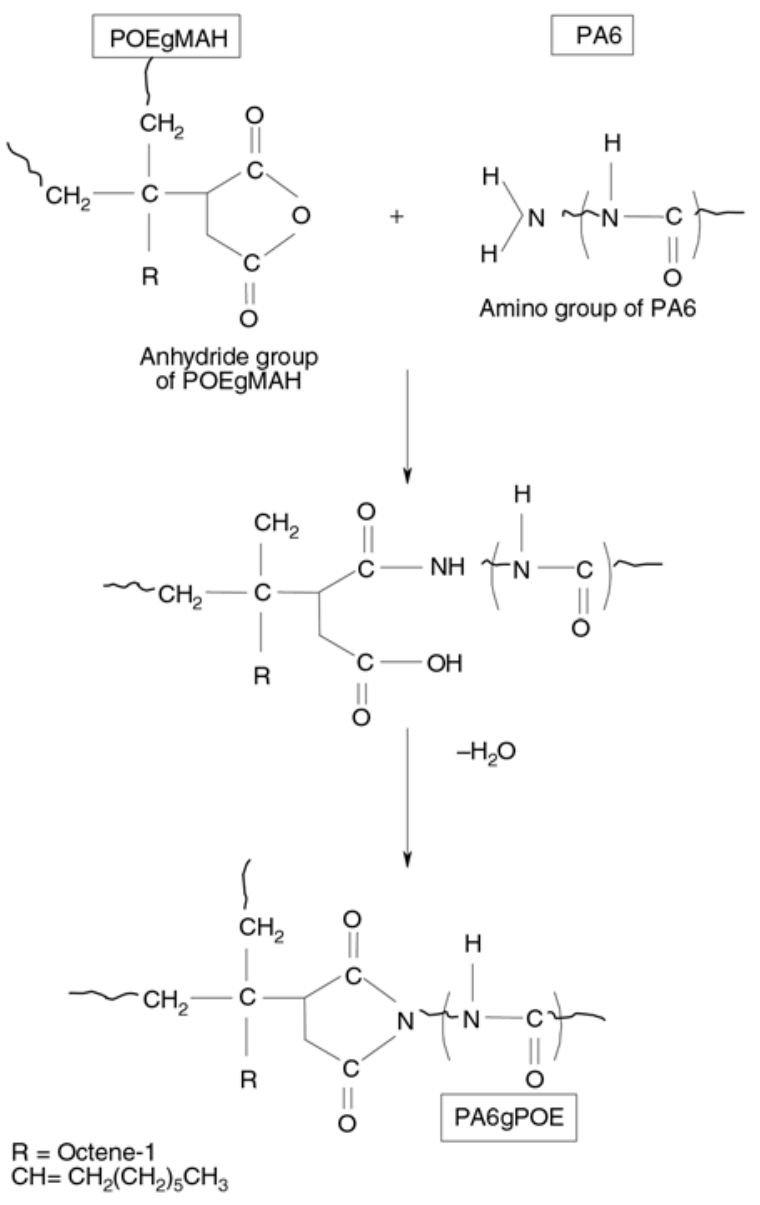

Figure 8. Possible chemical reactions between PA6 and POEgMAH

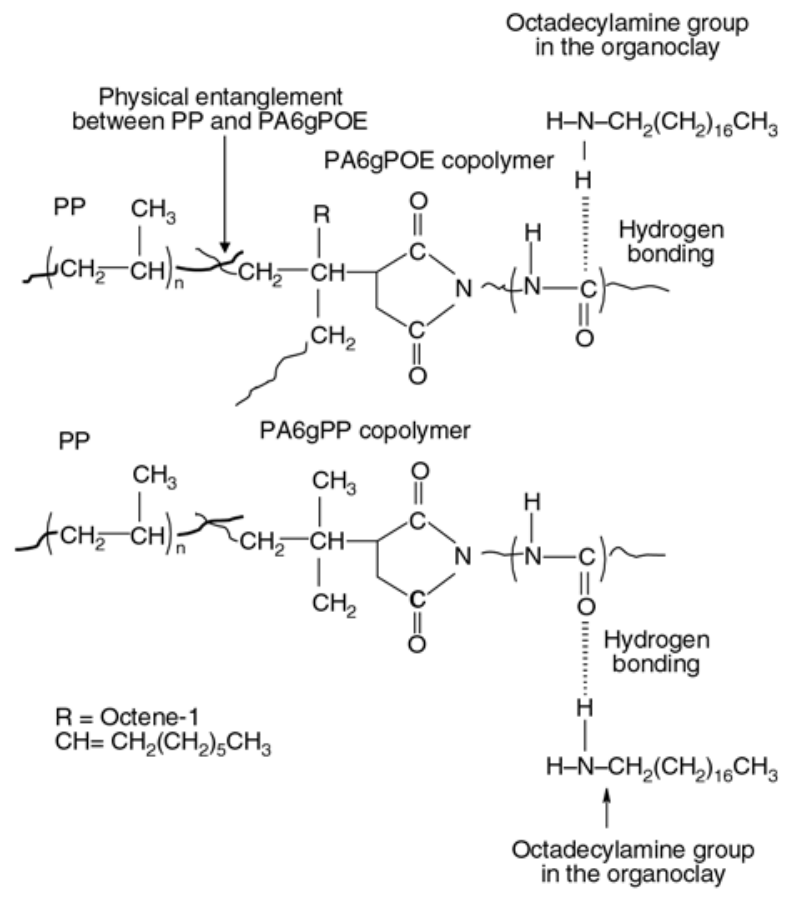

Figure 9. Interaction of PA6gPOE, PA6gPP, PP and organoclay 


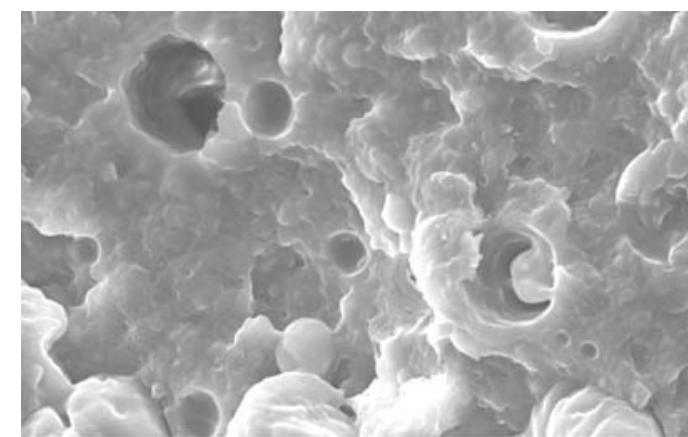

a)

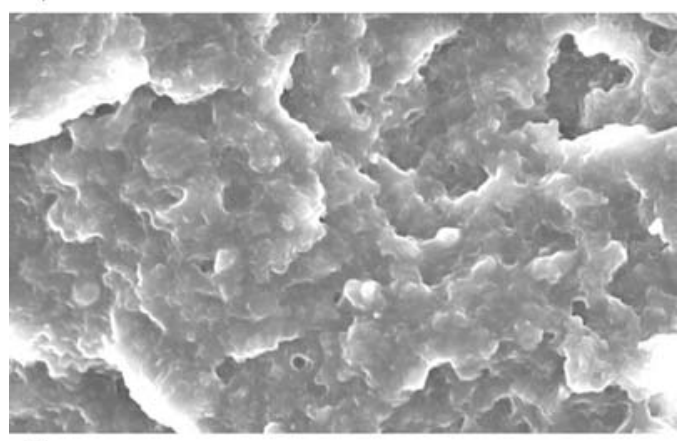

b)

Figure 10. SEM micrograph of cryogenically fractured surfaces of the PA6/PP/organoclay toughened by: a) POE, b) POEgMAH

phase boundary is almost indistinguishable in this blend.

From the measurement of a set of SEM micrographs on cryo-fractured surfaces, the size distribution of the POE domain is shown in Figure 11a. In comparison with maleated POE data in Figure 11b, the dispersed maleated POE phase exhibits a smaller size. The nanocomposites containing $10 \mathrm{wt} \%$ POEgMAH show a morphology of fine particles with an average diameter of $0.96 \mu \mathrm{m}$, which is relatively smaller than those observed in the nanocomposite blends of unmaleated POE $(1.50 \mu \mathrm{m})$ of the same composition (see Table 3 ). Besides that, the maleated POE particles are also
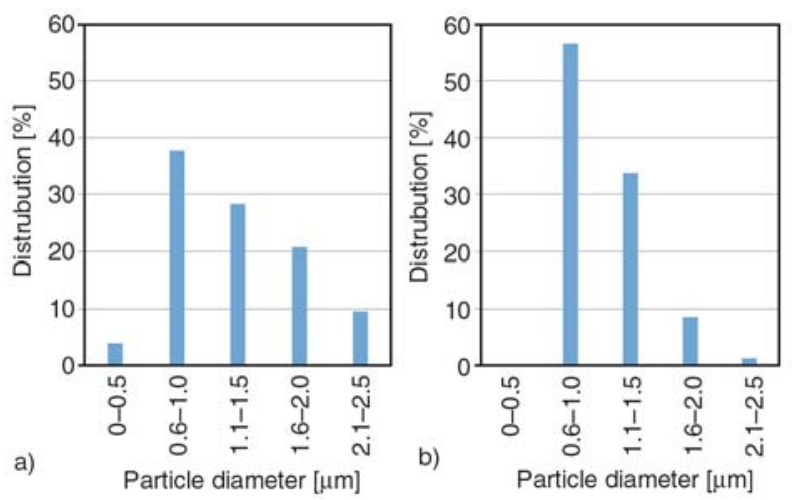

Figure 11. Histograms of elastomer particle size in $\mathrm{PA} 6 / \mathrm{PP} /$ organoclay a) POE, b) maleated POE
Table 3. The average of POE particle size in PA6/PP (70/30) nanocomposites with POE and POEgMAH

\begin{tabular}{|l|c|c|}
\hline Blend/Elastomer & $\begin{array}{c}\text { Diameter range } \\
{[\boldsymbol{\mu} \mathbf{m}]}\end{array}$ & $\begin{array}{c}\text { Average particle } \\
\text { diameter }[\boldsymbol{\mu m}]\end{array}$ \\
\hline $\mathrm{BC} / \mathrm{F} / \mathrm{E} 10$ & $0.50-2.30$ & 1.50 \\
\hline $\mathrm{BC} / \mathrm{F} / \mathrm{mE} 10$ & $0.65-2.00$ & 0.96 \\
\hline
\end{tabular}

more uniformly distributed as shown in Figure 11b. This conceptually suggested that the incorporation of POEgMAH makes the POE particles smaller and results in a finer dispersion of $\mathrm{POE}$ particles in the PA6/PP matrix due to the reduction of the interfacial tension of the blend. Similar findings have been reported for PA6/POEgMAH blends [26]. The enthalpy of the system that drove the POEgMAH grafted PA6 to the interface was reported to cause an increase in the interfacial area and a reduction in rubber particles size.

The SEM micrographs of the fracture surfaces taken after the impact test of the nanocomposites toughened with $20 \mathrm{wt} \%$ of POE and maleated POE are shown in Figure 12. It can be noted that the impact strength of the nanocomposites with $\mathrm{POE}$ is $6.8 \mathrm{~kJ} / \mathrm{m}^{2}$, while that of the nanocomposites with maleated POE is $37 \mathrm{~kJ} / \mathrm{m}^{2}$. It is evident that the morphologies of the fracture surfaces of the two blends are quite different. In case of the nanocom-
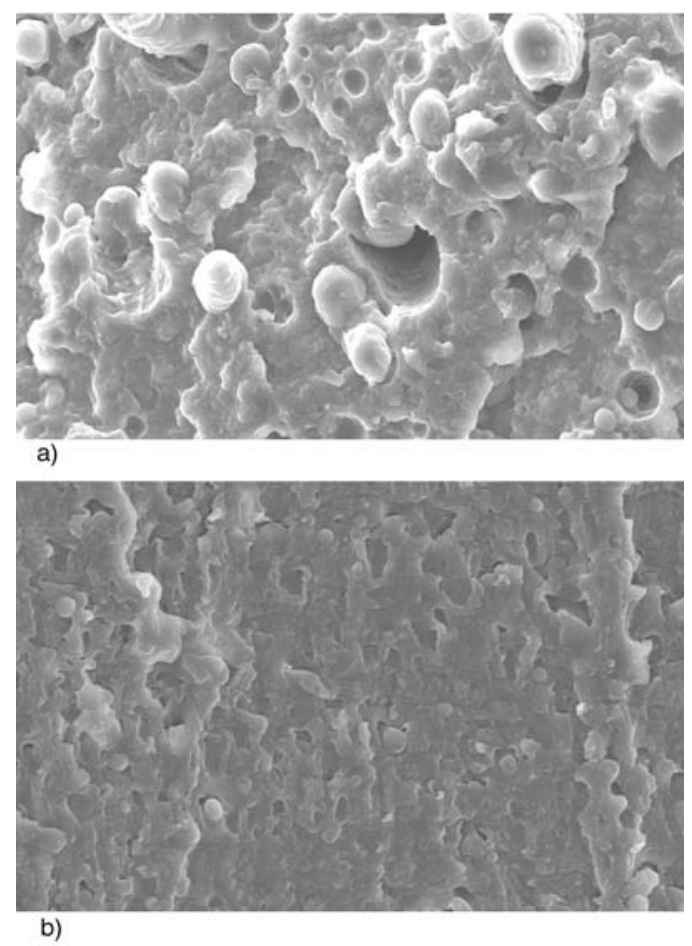

Figure 12. SEM micrograph of impact fracture surfaces of PA6/PP/organoclay with $20 \mathrm{wt} \%$ elastomer content a) POE, b) POEgMAH 
posites containing POE, large holes, formed by the removing of the POE particles, are clearly observed. Moreover, it can be seen that the fracture surface is smooth, indicating that the matrix PA6/PP fractures in a brittle manner during impact. In case of nanocomposites containing maleated POE, the holes are slightly elongated or distorted and the outline of the holes is indistinct. The higher value of elongation at breakage and impact strength obtained for the maleated POE may arise as a consequence of this elongated phase morphology of the maleated POE in the PA6/PP matrix. The significant difference in impact strength between POE and maleated POE can be ascribed to the fact that the former nanocomposite fractures in brittle mode, whereas the latter one fractures in ductile mode.

In order to have efficient stress transfer between two phases, the rubber particles should be well dispersed so that they can act efficiently as impact modifier, and they should also be well bonded to the polymer matrix [27]. The anhydride group of the POEgMAH is able to react with the PA6 terminal group to form POEgPA6 copolymer that strongly tends to concentrate at PA6/PP interfaces during melt processing [22]. According to Liang and $\mathrm{Li}$ [28], when rubber was grafted with a suitable content of maleic anhydride (MAH), the rubber particles were dispersed uniformly in the continuous PA6 matrix and PP was encapsulated by thin layers of rubber (i.e. in a shell-core structure). When highly dispersed, the rubbery phase acts as an effective stress concentrator and enhances both crazing and shear yielding in the matrix. Since both processes can dissipate a large amount of energy, there is a significant increase in the toughness of nanocomposites toughened with POEgMAH [24].

Figure 13 shows a proposed schematic illustration of the organoclay distribution in the PA6/PP blends with POE and maleated POE. However, at this point, there is no experimental evidence to substantiate this scheme. In the unmaleated POE system, as PA6 has a higher polarity than POE and PP, organoclay was well exfoliated in the PA6 matrix verified by the XRD results in our previous work $[7,14,15]$. No migration of the organoclay is expected into the dispersed POE during melt mixing. According to Chow et al. [3] and Li et al. [27], this is due to the strong interfacial interaction such as hydrogen bonding among hydroxyl groups of the

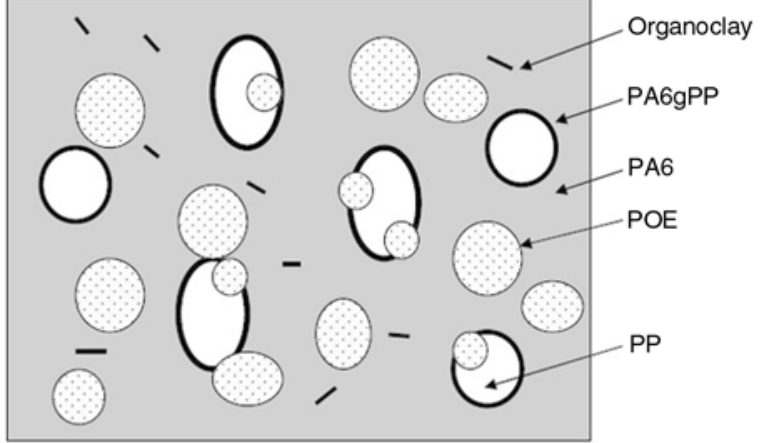

a)

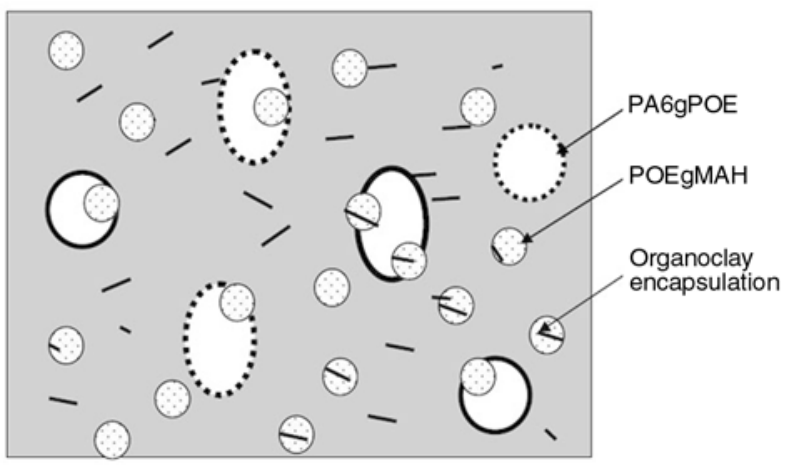

b)

Figure 13. Schematic of the morphology of PA6/PP/PPgMAH/organoclay a) with POE, b) with POEgMAH

organoclay and PA6 phase, which hinders the silicate crystallites in the PA6 matrix from migrating to the dispersed POE phase. Furthermore, there was no specific interaction between organoclay and POE because POE is non-polar. As a result, the microstructure with the separation between organoclay and POE is expected as it can be seen in Figure 13a.

However, for the maleated POE system, the presence of polar functional group (maleic anhydride) has improved the miscibility and adhesion between POE and organoclay [26, 29]. When the adhesion between POE and organoclay is enhanced, the organoclay becomes encapsulated by the maleated POE, promoting the formation of core-shell inclusions as illustrated in Figure 13b. These two different morphologies resulted in significantly distinct toughness properties. The POE nanocomposite systems with encapsulated structure have higher toughness than those having a separated structure.

\section{Conclusions}

Based on this work performed on the fracture behaviour of the rubber toughened PA6/PP nano- 
composites, the following conclusions can be drawn:

- The incorporation of organoclay has led to the expense Izod impact strength and the toughness $\left(K_{c}\right.$ and $G_{c}$ ) of the pure PA6/PP blends.

- Toughness increased with the increasing of elastomer concentration in both unmaleated and maleated POE. However, the increment in toughness is very significant for the maleated POE system particularly at higher POEgMAH loading. For example, the blend containing $20 \mathrm{wt} \%$ POEgMAH exhibited six times improvement of Izod impact strength compared to the pure PA6/PP/organoclay.

- Significant changes in blend morphology and toughness were obtained when POEgMAH was applied. The POEgMAH average particles size were $0.96 \mu \mathrm{m}$; smaller compared to that of $\mathrm{POE}$ $(1.50 \mu \mathrm{m})$ in PA6/PP/organoclay blends of the same composition, i.e. $10 \mathrm{wt} \%$ elastomer. A reduction in dispersed particle size and an increase in adhesion between the phases, brought about by the reaction between the amino group of PA6 and the anhydride group of POEgMAH during melt compounding succeed in forming PA6gPOE copolymer which was believed to be responsible for the toughness improvement of these blends.

\section{References}

[1] Alexandre M., Dubois P.: Polymer-layered silicate nanocomposites: Preparation, properties and uses of new class of materials. Materials Science and Engineering, 28, 1-63 (2000).

DOI: $10.1016 / \mathrm{S} 0927-796 \mathrm{X}(00) 00012-7$

[2] Lauke B.: On the effect of particle size on fracture toughness of polymer composites. Composites Science and Technology, 68, 3365-3372 (2008).

DOI: $10.1016 /$ j.compscitech.2008.09.011

[3] Chow W. S., Mohd Ishak Z. A., Karger-Kocsis J., Apostolov A. A., Ishiaku U. S.: Compatibilizing effect of maleated polypropylene on the mechanical properties and morphology of injection molded polyamide 6/polypropylene/organoclay nanocomposites. Polymer, 44, 7427-7440 (2003).

DOI: 10.1016/j.polymer.2003.09.006

[4] Chow W. S., Mohd Ishak Z. A.: Mechanical, morphological and rheological properties of polyamide 6/organo-montmorillonite nanocomposites. Express Polymer Letters, 1, 77-84 (2007).

DOI: 10.3144/expresspolymlett.2007.14
[5] Harmia T., Friedrich K.: Fracture toughness and failure mechanisms in unreinforced and long-glass-fibrereinforced PA66/PP blends. Composites Science and Technology, 53, 423-420 (1995).

DOI: 10.1016/0266-3538(95)00031-3

[6] Kusmono, Mohd Ishak Z. A., Chow W. S., Takeichi T., Rochmadi: Enhancement of properties of PA6/PP nanocomposites via organic modification and compatibilization. Express Polymer Letters, 2, 655-664 (2008).

DOI: 10.3144/expresspolymlett.2008.78

[7] Wahit M. U., Hassan A. Mohd Ishak Z. A., Rahmat A. R., Abu Bakar A.: Morphology, thermal, and Mechanical behavior of ethylene octene copolymer toughened polyamide 6/polypropylene nanocomposites. Journal of Thermoplastics Composites Materials, 19, 545-567 (2006). DOI: $10.1177 / 0892705706063927$

[8] Chen B., Evans J. R. G.: Impact and tensile energies of fracture in polymer-clay nanocomposites. Polymer, 49, 5113-5118 (2008).

DOI: 10.1016/j.polymer.2008.09.024

[9] González I., Eguiazábal J. I., Nazábal J.: Nanocomposites based on a polyamide 6/maleated styrenebutylene-co-ethylene-styrene blend: Effects of clay loading on morphology and mechanical properties. European Polymer Journal, 42, 2905-2913 (2006). DOI: 10.1016/j.eurpolymj.2006.07.014

[10] González I., Eguiazábal J. I., Nazábal J.: Rubbertoughened polyamide 6/clay nanocomposites. Composites Science and Technology, 66, 1833-1843 (2006).

DOI: $10.1016 /$ j.compscitech.2005.10.008

[11] González I., Eguiazábal J. I., Nazábal J.: Effects of the processing sequence and critical interparticle distance in PA6-clay/mSEBS nanocomposites. European Polymer Journal, 44, 287-299 (2008). DOI: $\underline{10.1016 / j . e u r p o l y m j .2007 .11 .027}$

[12] Bai S-L., Wang M.: Plastic damage mechanisms of polypropylene/polyamide 6/polyethylene octane elastomer blends under cyclic tension. Polymer, 44, 6537 6547 (2003). DOI: $\underline{10.1016 / \mathrm{S} 0032-3861(03) 00739-0}$

[13] Bai S-L., Wang G-T., Hiver J-M., G'Sell C.: Microstructures and mechanical properties of polypropylene/polyamide 5/polvethelene-octene elastomer blends. Polymer, 45, 3063-3071 (2004). DOI: $10.1016 /$ j.polymer.2004.02.070

[14] Wahit M. U., Hassan A., Mohd Ishak Z. A., Abu Bakar A.: The effect of polyethylene-octene elastomer on the morphological and mechanical properties of polyamide 6/polypropylene nanocomposites. Polymer and Polymer Composites, 13, 795-806 (2005). 
[15] Wahit M. U., Hassan A., Rahmat A. R., Lim J. W., Mohd Ishak Z. A.: Effect of organoclay and ethyleneoctene copolymer inclusion on the morphology and mechanical properties of polyamide/polypropylene blends. Journal of Reinforced Plastics and Composites, 25, 933-954 (2006). DOI: $\underline{10.1177 / 0731684406063529}$

[16] Cotterell B., Chia J. Y. H., Hbaieb K.: Fracture mechanisms and fracture toughness in semicrystalline polymer nanocomposites. Engineering Fracture Mechanics, 74, 1054-1078 (2007). DOI: 10.1016/j.engfracmech.2006.12.023

[17] Kwon S-C., Adachi T., Araki W., Yamaji A.: Effect of composing particles of two sizes on mechanical properties of spherical silica-particulate-reinforced epoxy composites. Composites Part B: Engineering, 39, 740-746 (2008).

DOI: $10.1016 /$ j.compositesb.2007.02.030

[18] ISO 13586: Plastics. Determination of fracture toughness $\left(\mathrm{G}_{\mathrm{IC}}\right.$ and $\left.\mathrm{K}_{\mathrm{IC}}\right)$ - Linear elastic fracture mechanics (LEFM) approach (2000).

[19] Wang H., Zeng C., Elkovitch M., Lee L. J., Koeling K. $\mathrm{W}$.: Processing and properties of polymer nano-composites. Polymer Engineering and Science, 41, 20362044 (2001).

DOI: $10.1002 /$ pen.10899

[20] Stevenson J. C.: Impact modifiers: Providing a boost to impact performance. Journal of Vinyl and Additive Technology, 1, 41-45 (1995).

[21] Gam K. T., Miyamoto M., Nishimura R., Sue H. J.: Fracture behavior of core-shell rubber-modified clayepoxy nanocomposites. Polymer Engineering and Science, 43, 1635-1645 (2003). DOI: $10.1002 /$ pen. 10137

[22] Ohlsson B., Hassander H., Törnell B.: Effect of the mixing procedure on the morphology and properties of compatibilized PP/PA blends. Polymer, 39, 47154721 (1998).

DOI: $10.1016 / \mathrm{S} 0032-3861(97) 10291-9$
[23] Yu Z-Z., Ke Y-C., Ou Y-C., Hu G-H.: Impact fracture morphology of nylon 6 toughened with a maleated polyethylene-octane elastomer. Journal of Applied Polymer Science, 76, 1285-1295 (2000).

DOI: 10.1002/(SICI)1097-4628(20000523)76:8<1285::

$$
\text { AID-APP9>3.0.CO;2-U }
$$

[24] Yu Z-Z., Lei M., Ou Y-C., Hu G-H.: The role of interfacial modifier in toughening of nylon- 6 with a coreshell toughened. Journal of Polymer Science Part B: Polymer Physic, 37, 2664-2672 (1999).

DOI: $10.1002 /(\mathrm{SICI}) 1099-0488(19990915) 37: 18<$ 2664::AID-POLB10>3.0.CO;2-O

[25] Yu Z-Z., Ou Y-C., Hu G-H.: Influence of interfacial adhesion on toughening of polyethylene-octane elastomer/nylon 6 blends. Journal of Applied Polymer Science, 69, 1711-1718 (1998).

DOI: 10.1002/(SICI)1097-4628(19980829)69:9<1711:: AID-APP4>3.0.CO;2-E

[26] Premphet-Sirisinha K., Chalearmthitipa S.: Study on composition and characteristics of maleated ethyleneoctane copolymer prepared by reactive extrusion on the morphology and properties of polyamide 6/ethylene-octane copolymer blends. Polymer Engineering and Science, 43, 317-328 (2003).

DOI: $10.1002 /$ pen. 10027

[27] Li F. Q., Kim D. G., Wu D. Z., Lu K., Jin R. G.: Effect of maleic anhydride graft ratio on mechanical properties and morphology of nylon 11/ethylene-octane copolymer blends. Polymer Engineering and Science, 41, 2155-2161 (2001).

DOI: $10.1002 /$ pen.10910

[28] Liang J. Z., Li R. K. Y.: Rubber toughening in polypropylene: A review. Journal of Applied Polymer Science, 77, 409-417 (2000).

DOI: 10.1002/(SICI)1097-4628(20000711)77:2<409:: AID-APP18>3.0.CO;2-N

[29] Long Y., Shanks R. A.: PP-elastomer-filler hybrids. I. Processing, microstructure, and mechanical properties. Journal of Applied Polymer Science, 61, $1877-$ 1885 (1996).

DOI: $\underline{10.1002 /(\text { SICI }) 1097-4628(19960912) 61: 11<}$ 1877::AID-APP3>3.0.CO;2-G 